\title{
Effects and possible mechanism of a picosecond pulsed electric field on angiogenesis in cervical cancer in vitro
}

\author{
LIMEI WU $^{1 *}$, YUTONG WU $^{1 *}$, ZHENGAI XIONG $^{1}$, CHENGUO YAO $^{2}$, \\ MANMAN ZENG ${ }^{3}$, RUIZHE ZHANG ${ }^{4}$ and YUANYUAN HUA ${ }^{1}$
}

\begin{abstract}
${ }^{1}$ Department of Obstetrics and Gynecology, The Second Affiliated Hospital of Chongqing Medical University, Chongqing 400010; ${ }^{2}$ State Key Laboratory of Power Transmission Equipment and System Security and New Technology, Chongqing University, Chongqing 400044; ${ }^{3}$ Department of Gynecology, Women and Children's Hospital of Guangdong,

Guangzhou, Guangdong 511442; ${ }^{4}$ Equipment Status Evaluation Center, Beijing Electric Power Research Institute, Beijing 100075, P.R. China
\end{abstract}

Received December 24, 2017; Accepted October 12, 2018

DOI: $10.3892 / \mathrm{ol} .2018 .9782$

\begin{abstract}
Picosecond pulsed electric field (psPEF) is an athermal, minimally invasive and local ablative biomedical engineering technique used in cancer therapy. However, to the best of our knowledge, the effect of psPEF on angiogenesis in cervical cancer is unknown. Therefore, the aim of the current study was to investigate the effects and possible mechanism of psPEF on angiogenesis in cervical cancer in vitro. HeLa cell and human umbilical vein endothelial cell (HUVEC) suspensions were exposed to psPEF with an increasing gradient of electric field intensity $(0,200,400$ and $600 \mathrm{kV} / \mathrm{cm})$. A Cell Counting kit- 8 assay and flow cytometry were used to investigate the effect of psPEF on the proliferation and apoptosis of HUVECs. The invasion, migration and tube formation capabilities of HUVECs following psPEF treatment were investigated by Transwell invasion assay, scratch test and lumen formation assay, respectively. Changes in the protein and mRNA levels of angiogenesis-associated factors in HeLa cells were detected by western blot analysis and reverse transcription-quantitative polymerase chain reaction. psPEF was identified to inhibit proliferation and tube formation, and induce apoptosis and necrosis of HUVECs in a dose-dependent manner. psPEF was revealed to decrease the protein and mRNA expression levels of vascular endothelial growth factor and hypoxia-inducible factor $1 \alpha$ in HeLa cells. In summary, psPEF exhibited anti-angiogenic effects in cervical cancer in vitro by exerting direct effects on HUVECs and indirect effects on angiogenesis-associated factors in HeLa cells.
\end{abstract}

Correspondence to: Dr Yuanyuan Hua, Department of Obstetrics and Gynecology, The Second Affiliated Hospital of Chongqing Medical University, 74 Linjiang Road, Yuzhong, Chongqing 400010, P.R. China

E-mail: 450892471@qq.com

*Contributed equally

Key words: uterine cervical neoplasms, pulsed field, tumor angiogenesis, human umbilical vein endothelial cells, HeLa cells

\section{Introduction}

Despite improvements due to an earlier diagnosis and improved treatment methods, cervical cancer remains a leading cause of cancer-associated mortality in women worldwide (1). Cervical cancer is preventable and often curable if it is detected early. However, a high proportion of patients exhibit a poor prognosis, as they are diagnosed with advanced stage, recurrent or persistent cervical cancer $(2,3)$. Therefore, there is a requirement for the development of novel treatment strategies.

Neovascularization serves an important role in the tumor progression, invasion and metastasis of cervical cancer (2). Although specific inhibitors of angiogenesis have been clinically approved, toxicity and disruption of the normal vascular bed limit their application (4). Traditional surgery often causes serious harm to the reproductive organs and may affect sexual function and fertility (5-7). Therefore, it is important to effectively treat and reduce the side effects of traditional cervical cancer treatments.

Picosecond pulsed electric field (psPEF) technology involves use of an ultra-broadband spectrum with a high time and spatial resolution, and low signal distortion. psPEF may be used to non-invasively and precisely target deep tissue (8). To the best of our knowledge, the biological effects of psPEF are not fully understood. Our preliminary study demonstrated that psPEF exhibits necrotic and anti-angiogenic effects in cervical cancer xenograft models by exerting direct effects on cancer cells and vascular endothelial cells, and indirect effects on angiogenesis-associated factors (9). However, to the best of our knowledge, the effects of psPEF on cervical cancer angiogenesis in vitro remain unknown. To investigate the effects and possible mechanism of psPEF on angiogenesis in cervical cancer in vitro, human umbilical vein endothelial cells (HUVECs) and HeLa cells were exposed to psPEF. The proliferation, cell motility and tube formation capabilities of HUVECs were analyzed. In addition, the protein and mRNA expression levels of angiogenesis-associated factors, including vascular endothelial growth factor (VEGF) and hypoxia-inducible factor $1 \alpha$ (HIF-1 $\alpha$ ), were measured in HeLa 
cells following psPEF treatment. By studying the underlying mechanism, the antitumor effect of psPEF may be improved, which may enhance its clinical application.

\section{Materials and methods}

Cell culture and materials. HeLa cells and HUVECs were purchased from The Cell Bank of Type Culture Collection of Chinese Academy of Sciences (Shanghai, China) and cultured in high glucose Dulbecco's modified Eagle's medium (DMEM; Invitrogen; Thermo Fisher Scientific, Inc., Waltham, MA, USA) supplemented with $10 \%$ fetal bovine serum (GE Healthcare Life Sciences, Logan, UT, USA) and $1 \%$ penicillin-streptomycin at $37^{\circ} \mathrm{C}$ in a $5 \% \mathrm{CO}_{2}$ incubator. Cell Counting kit-8 (CCK-8; Guangzhou Yiyuan Biological Technology Co., Ltd., Guangzhou, China), the Annexin V-fluorescein isothiocyanate (FITC) apoptosis detection kit (Nanjing KeyGen Biotech Co., Ltd., Nanjing, China), the anti-VEGF polyclonal antibody (no. bs-0279R; 1:200 dilution; Beijing Biosynthesis Biotechnology Co., Ltd., Beijing, China) and the anti-HIF-1 $\alpha$ monoclonal antibody (cat. no. sc-13515; 1:500 dilution; Santa Cruz Biotechnology, Inc., Dallas, TX, USA) were used in the current study.

Field stimulation protocol. The following parameters were fixed: i) Frequency, 3 hertz; ii) duration, 800 picosec; and iii) pulse number, 2,000. Cells were randomly divided into four groups: The 200, 400 and $600 \mathrm{kV} / \mathrm{cm}$ psPEF treatment groups, and a control group that was administered no treatment. Following three washes with PBS, cells were combined with $0.125 \%$ trypsin-EDTA, and then centrifuged at $800 \mathrm{x} \mathrm{g}$ for $5 \mathrm{~min}$ at room temperature. Cells were then resuspended in fresh high glucose DMEM at a concentration of $1 \times 10^{6}$ cells $/ \mathrm{ml}$. Subsequently, the cell suspension $(200 \mu \mathrm{l})$ was placed into a cuvette and power was supplied. The electric field amplitude and pulse width of psPEF was monitored throughout the experiment using a DP04054 oscilloscope (Tektronix, Inc., Beaverton, OR, USA). The control group was not connected to the power supply.

CCK-8 assay. Following psPEF treatment, the cell viability was investigated. HUVECs were transferred to 96-well plates containing $150 \mu \mathrm{l}$ DMEM and $1 \times 10^{4}$ cells per well, and cultured for $2,4,6,8,10,12,14$ or $16 \mathrm{~h}$ in a $5 \% \mathrm{CO}_{2}$ humidified incubator at $37^{\circ} \mathrm{C}$. Normal control (without psPEF treatment) and blank groups (without cells) were also included. Following incubation, $20 \mu \mathrm{l}$ CCK- 8 was added to each well and incubated for a further $2 \mathrm{~h}$ at $37^{\circ} \mathrm{C}$. The optical density was measured at $470 \mathrm{~nm}$ using an ELx800 absorbance microplate reader (BioTek Instruments, Inc., Winooski, VT, USA).

Apoptosis analysis. HUVECs were grown in $25-\mathrm{cm}^{2}$ culture flasks for $12 \mathrm{~h}$ after treatment in a $5 \% \mathrm{CO}_{2}$ humidified incubator at $37^{\circ} \mathrm{C}$. Cells were double-stained using an Annexin V-FITC apoptosis detection kit, according to the manufacturer's protocol. The cellular fluorescence was measured at an emission wavelength of $530 \mathrm{~nm}$ and an excitation wavelength of $488 \mathrm{~nm}$ using BD FACScan system (BD Biosciences, Franklin Lakes, NJ, USA) equipped with CellQuest Pro software version 5.1 (BD Biosciences, Franklin Lakes, NJ, USA).

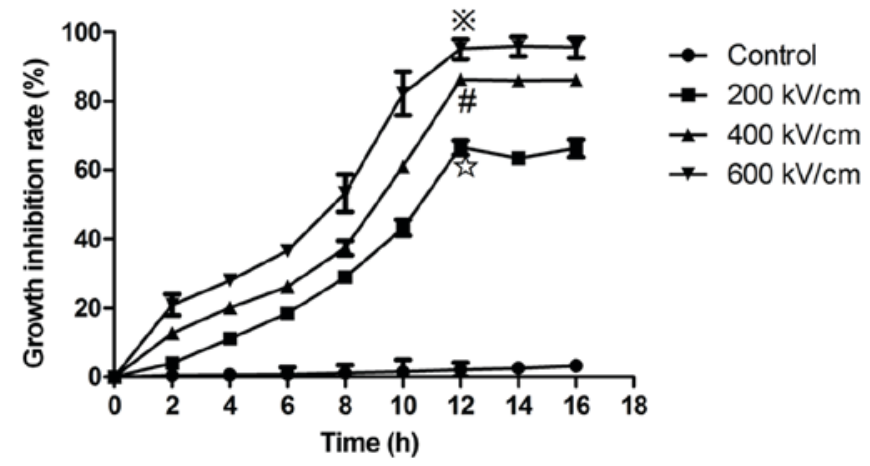

Figure 1. Growth inhibition rate of human umbilical vein endothelial cells measured by Cell Counting kit- 8 assay following psPEF treatment. Cells were treated with different psPEF intensities $(200,400$ and $600 \mathrm{kV} / \mathrm{cm})$ and cultured for different durations $(2,4,6,8,10,12,14$ and 16 h). Following $12 \mathrm{~h}$, the growth inhibition rate was measured. Data are presented as the mean \pm standard deviation. psPEF, picosecond pulsed electric field.

In vitro migration assay. Transwell invasions assay were conducted in 24-well cell culture inserts The upper chamber with polycarbonate membrane ( $8 \mathrm{~mm}$ pore size) (Corning Incorporated, Corning, NY, USA) were covered with $40 \mu \mathrm{l}$ Matrigel (1:4 dilution; BD Biosciences, Franklin Lakes, NJ, USA) and incubated for $24 \mathrm{~h}$ at $37^{\circ} \mathrm{C}$. The lower chamber was filled with $750 \mu$ l DMEM with 10\% FBS. Following psPEF treatment, the HUVECs cells were harvested and plated in complete medium on top of the culture insert at $5 \times 10^{4}$ cells per insert in $0.5 \mathrm{ml}$. The inserts were incubated at $37^{\circ} \mathrm{C}, 5 \% \mathrm{CO}_{2}$ for $18 \mathrm{~h}$. Non-invading cells were removed. Cells that had migrated through the pores were fixed with $4 \%$ paraformaldehyde for $30 \mathrm{~min}$, stained in $0.5 \%$ crystal violet (Beyotime Institute of Biotechnology, Shanghai, China) for $10 \mathrm{~min}$ at room temperature and counted on a Leica CME microscope at total magnification, $\mathrm{x} 40$. Three inserts were counted for each group and the experiment was repeated a minimum of three times.

In vitro wound-healing assay. Following psPEF treatment and incubation for $12 \mathrm{~h}$ in a $5 \% \mathrm{CO}_{2}$ humidified incubator at $37^{\circ} \mathrm{C}$, HUVECs were harvested, counted, plated at $4 \times 10^{5} \mathrm{cells} / \mathrm{ml}$ in 12 -well dishes and incubated overnight at $37^{\circ} \mathrm{C}$. Images were captured with a Leica CME microscope at x20 total magnification immediately after wounds had been made with a pipette tip and following $24 \mathrm{~h}$, and the distance migrated by the cells during this period was measured. The distance migrated by the psPEF treatment groups was calculated relative to the control group and expressed as the migration index. The experiment was repeated a minimum of three times.

Lumen formation test. The lumen formation assay was performed as described previously by Arnaoutova et al (10). Briefly, following psPEF treatment, HUVEC suspensions from the four treatment groups were added to the top of the gel at a density of 15,000 cells/well, incubated for $3 \mathrm{~h}$ in a $5 \% \mathrm{CO}_{2}$ humidified incubator at $37^{\circ} \mathrm{C}$ and then imaged with a Leica $\mathrm{CME}$ microscope at total magnification, $\mathrm{x} 20$.

Western blot analysis and reverse transcription-quantitative polymerase chain reaction (RT-qPCR). HeLa cells from four groups (control, 200,400 and $600 \mathrm{kV} / \mathrm{cm}$ psPEF tretment groups) 

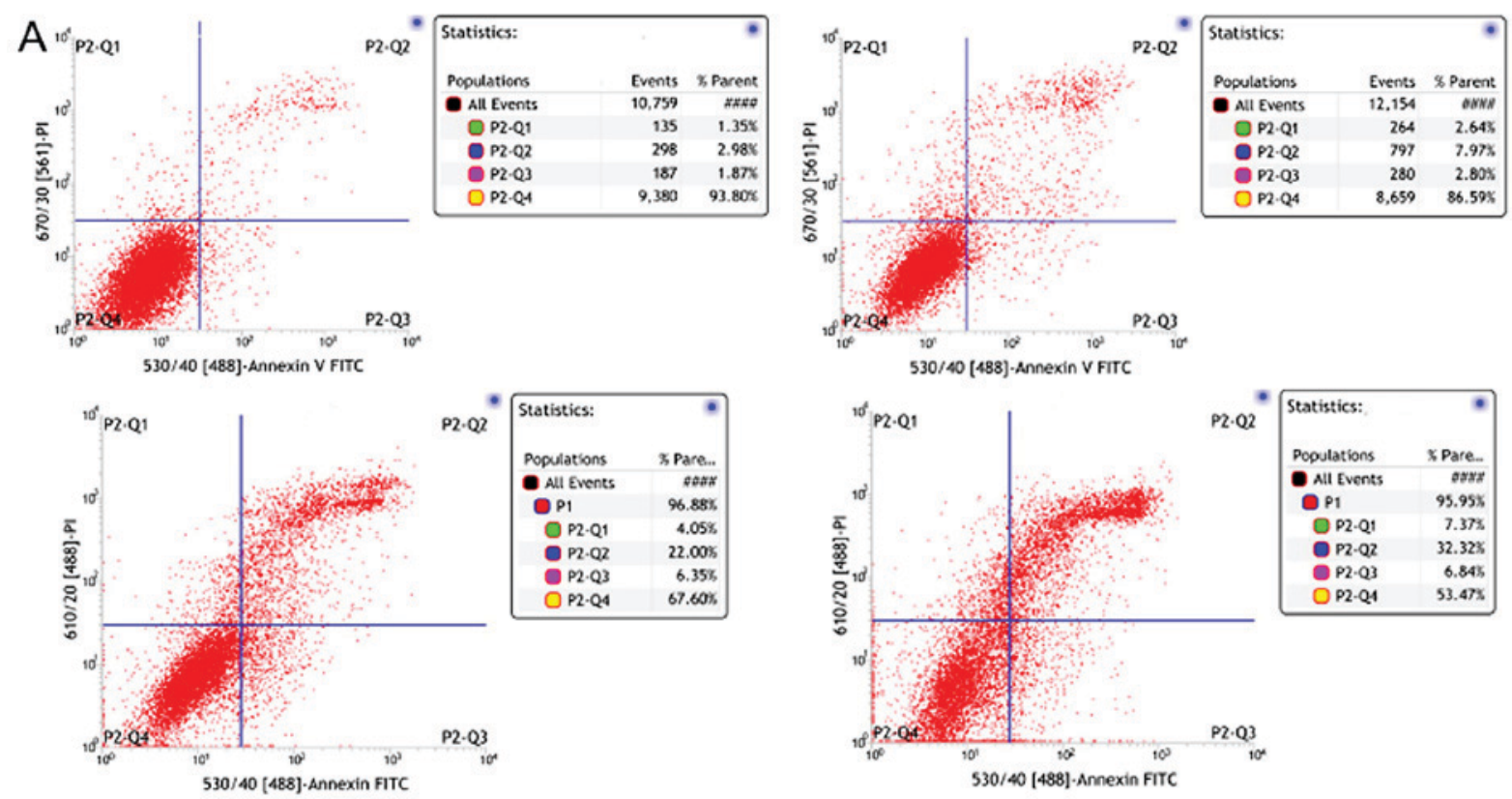

B

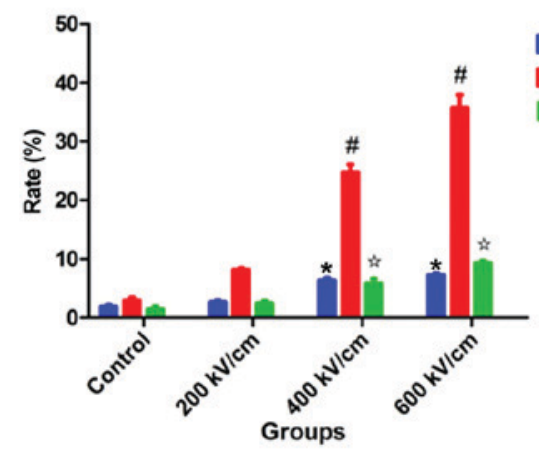

Figure 2. Apoptosis and necrosis rates of HUVECs following psPEF treatment analyzed by flow cytometry. (A) Representative flow cytometry plots of the four groups (top left, top right, bottom left and bottom right represented Control, 200, 400 and $600 \mathrm{kV} / \mathrm{cm}$ psPEF treatment group, respectively). P2-Q1 represents necrosis, P2-Q2 represents late apoptosis, P2-Q3 represents initial apoptosis and P2-Q4 represents normal cells. (B) The mean initial apoptosis rate, late apoptosis rate and necrosis rate of HUVECs following psPEF treatment. The apoptosis and necrosis rates were significantly increased in the 400 and $600 \mathrm{kV} / \mathrm{cm}$ treatment groups compared with those in the control group. Data are presented as the mean \pm standard deviation. ${ }^{*} \mathrm{P}<0.01$ vs. control initial apoptosis rate, ${ }^{\text {"}} \mathrm{P}<0.01$ vs. control late apoptosis rate, ${ }^{\mathrm{t}} \mathrm{P}<0.01$ vs. control necrosis rate. HUVEC, human umbilical vein endothelial cell; psPEF, picosecond pulsed electric field; FITC, fluorescein isothiocyanate.

were used. Western blot analysis and RT-qPCR were performed as described previously (11). The internal loading control was $\beta$-tubulin and bands were analyzed using Quantity One 4.6.2 software (Bio-Rad laboratories, Inc., Hercules, CA, USA). The primers used for RT-qPCR were as follows: VEGF forward, 5'-GTCCCAGGCTGCACCCATG-3' and reverse, 5'-AGG AAGCTCATCTCTCCTA-3'; and HIF-1 $\alpha$ forward, 5'-TCC ATGTGACCATGAGGAAA-3' and reverse, 5'-CCAAGCAGG TCATAGGTGGT-3'. $\beta$-tubulin forward, 5'-CCAAGGGTC ACTACACG-3' and reverse, 5'-GCAGTCGCAGTTTTCACA CTC-3'; all data were normalized to the tubulin expression levels. Each experiment was performed in triplicate.

Statistical analysis. All data were analyzed using SPSS software (version 10.0; SPSS, Inc., Chicago, IL, USA) and expressed as the mean \pm standard deviation of a minimum of three independent experiments. Statistical analysis was carried out by one-way analysis of variance (ANOVA), followed by Tukey's post-hoc test for multiple group comparisons, $\mathrm{P}<0.01$ was considered to indicate a statistically significant difference.

\section{Results}

psPEF is associated with reduced cell survival. HUVECs were exposed to psPEF and cultured for 2, 4, 6, 8, 10, 12, 14 or $16 \mathrm{~h}$. The CCK-8 assay was then used to analyze cell viability. The cell survival rate was taken as $100 \%$ for the control group. The cell growth inhibition rate was determined as: (The absorbance of normal control cells-the absorbance of psPEF treatment cells)/(the absorbance of normal control cells-the absorbance of the blank group) $\mathrm{x} 100$. The results indicated that psPEF inhibited the growth of HUVECs in an electric field amplitude-dependent manner. An increased growth inhibition rate was associated with higher electric field amplitude and the maximum cell inhibition was observed at $12 \mathrm{~h}$ after psPEF treatment. The cells growth inhibition rate of the control, and the 200, 400 and $600 \mathrm{kV} / \mathrm{cm}$ psPEF treatment groups at $12 \mathrm{~h}$ following treatment with $\mathrm{psPEF}$ were $2.14 \pm 1.98,66.53 \pm 0.2 .12,86.32 \pm 1.14$ and $95.14 \pm 2.93 \%$, respectively ( $* \mathrm{P}<0.01$, vs. the control, 200 and $400 \mathrm{kV} / \mathrm{cm}$ groups; ${ }^{\text {" }} \mathrm{P}<0.01$, vs. the control and $200 \mathrm{kV} / \mathrm{cm}$ groups; ${ }^{2} \mathrm{P}<0.01$, vs. the control group; Fig. 1). 


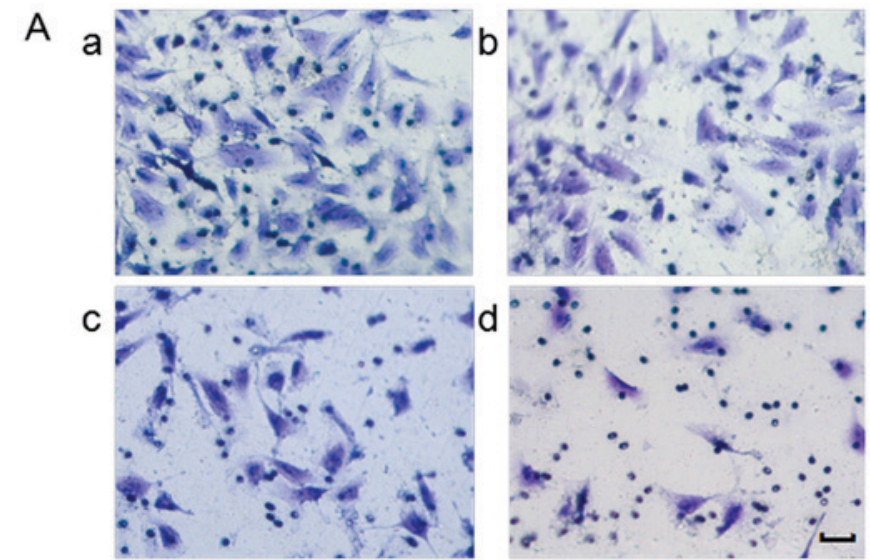

B

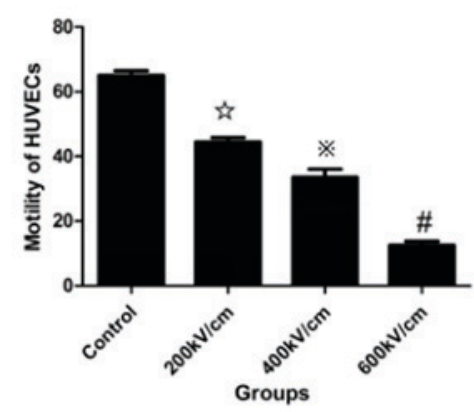

Figure 3.Influence of psPEF on the motility of HUVECs.(Aa-d) Representative motility assay images of the control, and the 200, 400 and $600 \mathrm{kV} / \mathrm{cm}$ psPEF treatment groups, respectively. Magnification, $x 400$. Stained with crystal violet for $10 \mathrm{~min}$ at room temperature. (B) Motility of HUVECs in the four groups. The motility of HUVECs treated with 400 and $600 \mathrm{kV} / \mathrm{cm}$ psPEF was significantly decreased compared with that of the control group. Data are expressed as the mean \pm standard deviation. ${ }^{*} \mathrm{P}<0.01$ vs. control, 400 and $600 \mathrm{kV} / \mathrm{cm}$ groups. ${ }^{*} \mathrm{P}<0.01 \mathrm{vs}$. control and $600 \mathrm{kV} / \mathrm{cm}$ groups. ${ }^{\#} \mathrm{P}<0.01$ vs. control and $400 \mathrm{kV} / \mathrm{cm}$ group. psPEF, picosecond pulsed electric field; HUVEC, human umbilical vein endothelial cell.

psPEF induces apoptosis and necrosis of HUVECs. As demonstrated in Fig. 2, the apoptosis and necrosis rates of HUVECs following psPEF treatment were analyzed by flow cytometry. The mean initial apoptosis rates of the control, and the 200, 400 and $600 \mathrm{kV} / \mathrm{cm}$ psPEF treatment groups were $1.91 \pm 0.69$, $2.74 \pm 0.42,5.86 \pm 1.37$ and $7.29 \pm 0.61 \%$, respectively. The mean late apoptosis rates of the four groups were $3.00 \pm 0.81,8.17 \pm 0.57$, $24.71 \pm 2.39$ and $35.83 \pm 3.65 \%$, respectively. The mean necrosis rates of the four groups were $1.43 \pm 0.87,2.49 \pm 0.80,5.86 \pm 1.37$ and $9.40 \pm 0.61 \%$, respectively. The initial apoptosis, late apoptosis and necrosis rates were significantly increased in the 400 and $600 \mathrm{kV} / \mathrm{cm}$ treatment groups compared with the control group. In summary, the results indicated that psPEF could induce apoptosis and necrosis of HUVECs.

psPEF treatment impairs cell motility. A migration assay (Fig. 3) and in vitro wound-healing assay (Fig. 4) were used to assess the effects of psPEF on the motility of HUVECs. In the migration assay, the number of cells that moved across a microporous membrane following psPEF treatment was recorded. The data are expressed as motility indexes, which represent the number of cells that moved across the membranes relative to the control. The motility index of the control, and the 200, 400 and $600 \mathrm{kV} / \mathrm{cm}$ psPEF treatment groups was $65.11 \pm 2.43,44.52 \pm 2.26$, $33.63 \pm 4.17$ and $12.52 \pm 2.13 \%$, respectively. A statistically

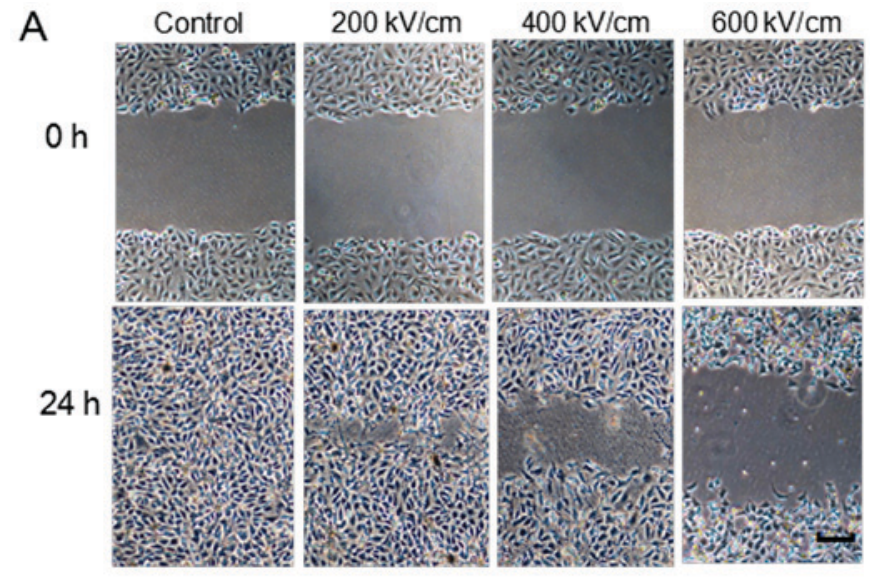

B

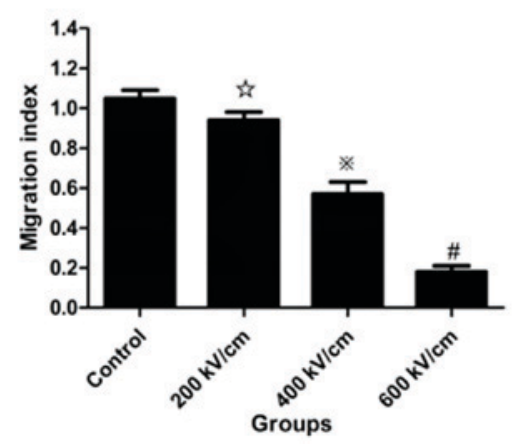

Figure 4. psPEF inhibits wound healing of human umbilical vein endothelial cells. (A) At $0 \mathrm{~h}$, a wound was made by a pipette tip and the distance migrated by the cell monolayer was measured $24 \mathrm{~h}$ after psPEF treatment. Magnification, x200. (B) Distances migrated by the psPEF treatment groups were calculated relative to the control. Data are expressed as the mean \pm standard deviation ${ }^{\wedge} \mathrm{P}<0.01$ vs. control, 400 and $600 \mathrm{kV} / \mathrm{cm}$ groups. * $\mathrm{P}<0.01$ vs. Control and $600 \mathrm{kV} / \mathrm{cm}$ groups. ${ }^{~} \mathrm{P}<0.01$ vs. $400 \mathrm{kV} / \mathrm{cm}$ group. psPEF, picosecond pulsed electric field.

significant difference was identified in the motility index of the 400 and $600 \mathrm{kV} / \mathrm{cm}$ psPEF treatment groups compared with the control group $(\mathrm{P}<0.01)$. In the wound-healing assay, the distance moved by the wounded cells following treatment with different psPEF intensities was measured. The migration index for the control, and the 200, 400 and $600 \mathrm{kV} / \mathrm{cm}$ psPEF treatment groups was $1.05 \pm 0.04,0.94 \pm 0.04,0.57 \pm 0.06$ and $0.18 \pm 0.03 \%$, respectively. A statistically significant difference was identified in the 400 and $600 \mathrm{kV} / \mathrm{cm}$ psPEF treatment groups compared with the control group $(\mathrm{P}<0.01)$.

psPEF inhibits tube formation in HUVECs. Differences in tube formation were identified between the control and psPEF treatment groups (Fig. 5). HUVECs in the control group demonstrated adhesion and alignment (Fig. 5Aa). However, the psPEF-treated cells appeared less elongated and an inhibition of tube formation was identified (Fig. 5Ab-d). An increase in the psPF electric field intensity was associated with a decreased number of tubes. The mean number of tubes formed for the control, and the 200,400 and $600 \mathrm{kV} / \mathrm{cm}$ psPEF treatment groups was $13.31 \pm 1.53,7.23 \pm 0.58,3.42 \pm 0.75$ and $1.02 \pm 0.44$, respectively (Fig. 5B). A statistically significant difference was identified between the control group and all psPEF treatment groups $(\mathrm{P}<0.01)$. These results indicated that $\mathrm{psPEF}$ inhibited tube formation in HUVECs. 


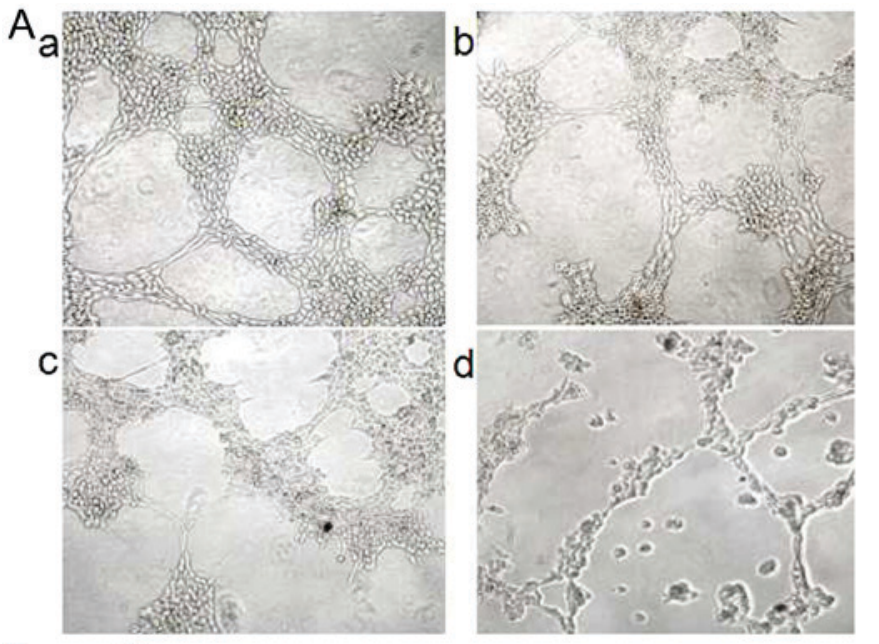

B

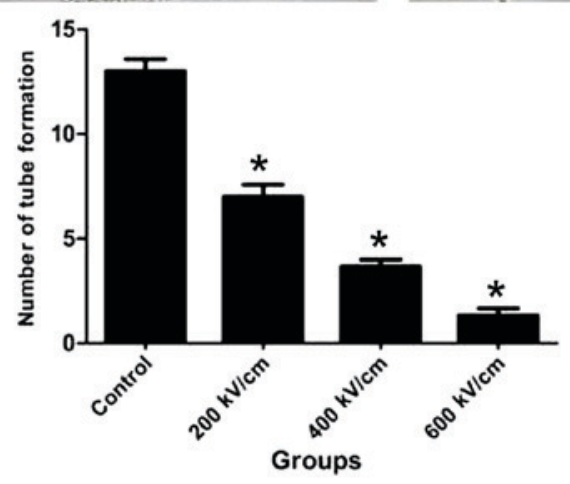

Figure 5. Endothelial tube formation assay. (Aa-d) Representative images of HUVEC tube formation in the control, and the 200,400 and $600 \mathrm{kV} / \mathrm{cm} \mathrm{psPEF}$ treatment groups, respectively. Magnification, x200. (B) The mean number of tubes formed following psPEF treatment. The mean tube number significantly decreased with an increase in the psPEF electric field intensity, which indicated that psPEF treatment inhibited HUVEC tube formation. Data are expressed as the mean \pm standard deviation ${ }^{*} \mathrm{P}<0.01$ vs. control. HUVEC, human umbilica vein endothelial cell; psPEF, picosecond pulsed electric field.

psPEF reduces the protein and $m R N A$ levels of VEGF and $H I F-1 \alpha$ in HeLa cells. The protein and mRNA levels of VEGF and HIF-1 $\alpha$ in HeLa cells were measured following psPEF treatment. Western blot analysis revealed that the protein levels of VEGF and HIF-1 $\alpha$ were decreased in the 400 and $600 \mathrm{kV} / \mathrm{cm}$ groups compared with those in the control group (Fig. 6A). RT-qPCR identified that the mRNA levels of VEGF and HIF-1 $\alpha$ were significantly decreased in the 400 and $600 \mathrm{kV} / \mathrm{cm}$ groups compared with those in the control group ( $\mathrm{P}<0.01$; Fig. 6B).

\section{Discussion}

Angiogenesis serves an important role in tumor invasion and metastasis, and is essential for tumor growth $>1-2 \mathrm{~mm}^{3}(12,13)$. Folkman et al (12) reported that tumor growth requires tumor cell proliferation and angiogenesis. The basic requirement for angiogenesis is the proliferation and migration of vascular endothelial cells (14-17). Therefore, blocking these processes in vascular endothelial cells may inhibit tumor vascularization.

In the current study, psPEF inhibited the proliferation of HUVECs in a dose- and time-dependent manner. Furthermore, psPEF impaired the motility of HUVECs in a dose-dependent manner. Tumor blood vessels are predominantly composed of vascular endothelial cells; therefore, direct inhibition of
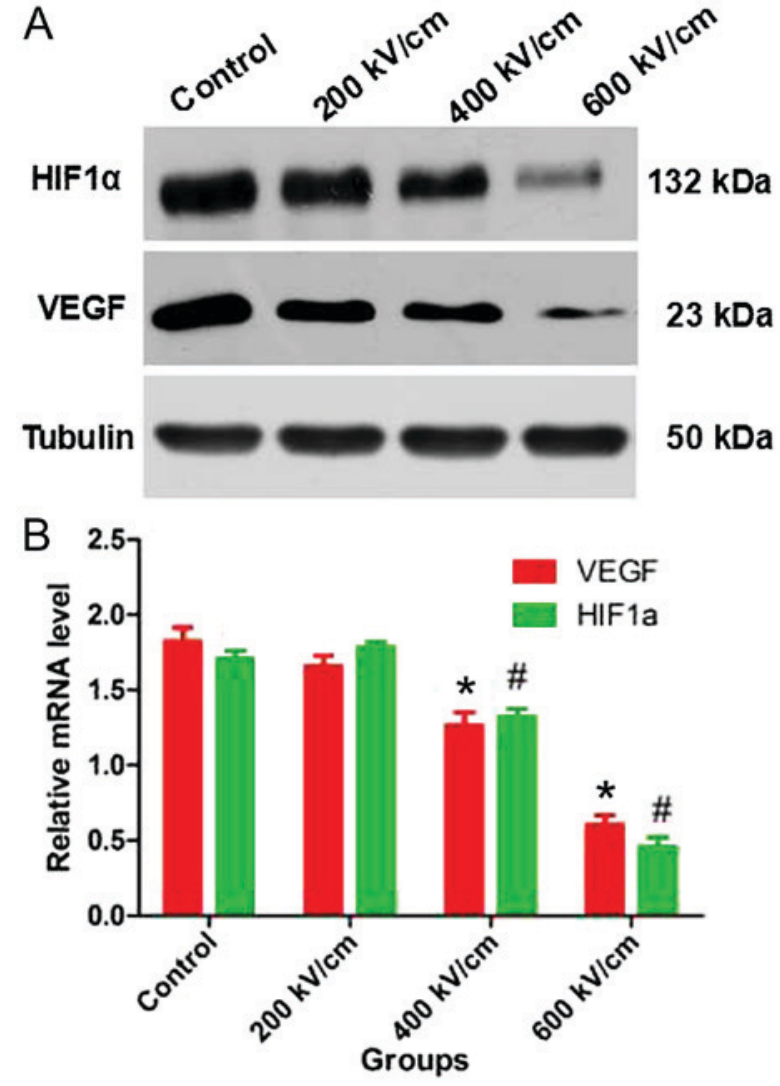

Figure 6. Effect of different psPEF intensities on protein and mRNA levels of HIF-1 $\alpha$ and VEGF. (A) Protein expression levels of VEGF and HIF-1 $\alpha$ in psPEF-treated HeLa cells were detected by sodium dodecyl sulfate-polyacrylamide gel electrophoresis analysis. (B) mRNA expression levels of VEGF and HIF-1 $\alpha$ in psPEF-treated HeLa cells were normalized to the control group. Data are expressed as the mean \pm standard deviation $(n=3)$. ${ }^{*} \mathrm{P}<0.01$ vs. VEGF control, ${ }^{*} \mathrm{P}<0.01$ vs. HIF- $1 \alpha$ control. psPEF, picosecond pulsed electric field; HIF-1 $\alpha$, hypoxia-inducible factor $1 \alpha$; VEGF, vascular endothelial growth factor.

tumor vascular endothelial cell growth is an important target to inhibit tumor growth, invasion and metastasis (13). The current study investigated whether psPEF may inhibit the angiogenesis of HUVECs using the lumen formation test. The results demonstrated that a decrease in the number of tubes was associated with an increase in the psPEF electric field intensity. Our previous study indicated that psPEF could induce apoptosis through a mitochondrial-mediated pathway in HeLa cells (11). In the current study, the apoptosis rate of HUVECs, particularly the late apoptosis rate, increased significantly compared with that of the control group. However, to the best of our knowledge, the underlying mechanism of this remains unknown.

Impairment of blood flow leads to tumor cell death due to a lack of nutrients and an accumulation of catabolite products $(18,19)$. The inhibition of angiogenesis-associated factors inhibits blood flow, which leads to tumor growth inhibition (20). Hypoxia is considered to serve as a driving force for tumor angiogenesis (21). Tumor cells can adapt to hypoxia by altering the transcription of genes associated with angiogenesis, including VEGF and HIF-1 $\alpha$ (22-25). In the current study, the protein and mRNA levels of VEGF and HIF-1 $\alpha$ in HeLa cells were measured following treatment with psPEF. The results revealed that psPEF treatment is associated with decreased protein and mRNA 
levels of VEGF and HIF-1 $\alpha$. Therefore, we hypothesize that psPEF may indirectly decrease angiogenic activity in vitro by downregulating angiogenesis-associated factors in HeLa cells, which is consistent with our previous animal study (9).

In summary, the current study demonstrated that psPEF exhibited anti-angiogenesis effects in cervical cancer cells by two mechanisms. Firstly, psPEF exhibited a direct anti-angiogenic effect in vitro on HUVECs. Secondly, psPEF treatment was associated with a downregulation of angiogenesis-associated factors secreted by cancer cells, which suggests that psPEF could indirectly inhibit the formation of tumor vessels in vitro.

\section{Acknowledgements}

Not applicable.

\section{Funding}

The present study was supported by the National Natural Science Foundation of China (grant no. 81301928) and the Project Foundation of Chongqing Municipal Education Committee (grant no. KJ1500210).

\section{Availability of data and materials}

The datasets used and/or analyzed during the present study are available from the corresponding author on reasonable request.

\section{Authors' contributions}

ZX, CY and YH designed the experiments. LW, YW, MZ and RZ performed the experiments and collected data. CY, YH, LW, YW and RZ analyzed and interpreted the data. LW and YW drafted the manuscript. YH, ZX, LW and MZ revised the paper critically for important intellectual content. LW YW and YH agreed to be accountable for all aspects of the work in ensuring that questions related to the accuracy or integrity of any part of the study are appropriately investigated and resolved. All authors read and gave final approval of the version to be published.

\section{Ethics approval and consent to participate}

Not applicable.

\section{Patient consent for publication}

Not applicable.

\section{Competing interests}

The authors declare that they have no competing interests.

\section{References}

1. Landt S, Wehling M, Heidecke H, Jeschke S, Korlach S, Stöblen F, Schmid P, Blohmer JU, Lichtenegger W, Sehouli J and Kümmel S: Prognostic significance of angiogenic factors in uterine cervical cancer. Anticancer Res 31: 2589-2595, 2011.
2. Monk BJ, Willmott LJ and Sumner DA: Anti-angiogenesis agents in metastatic or recurrent cervical cancer. Gynecol Oncol 116: 181-186, 2010.

3. Monk BJ and Herzog TJ: The evolution of cost-effective screening and prevention of cervical carcinoma: Implications of the 2006 consensus guidelines and human papillomavirus vaccination. Am J Obstet Gynecol 197: 337-339, 2007.

4. Ackermann M, Carvajal IM, Morse BA, Moreta M, O'Neil S, Kossodo S, Peterson JD, Delventhal V, Marsh HN, Furfine ES and Konerding MA: Adnectin CT-322 inhibits tumor growth and affects microvascular architecture and function in Colo205 tumor xenografts. Int J Oncol 38: 71-80, 2011.

5. Verheul HM and Pinedo HM: Possible molecular mechanisms involved in the toxicity of angiogenesis inhibition. Nat Rev Cancer 7: 475-485, 2007.

6. Ma J and Waxman DJ: Combination of antiangiogenesis with chemotherapy for more effective cancer treatment. Mol Cancer Ther 7: 3670-3684, 2008.

7. Seol HJ,Ulak R,Ki KD and Lee JM: Cytotoxic and targeted systemic therapy in advanced and recurrent cervical cancer: Experience from clinical trials. Tohoku J Exp Med 232: 269-276, 2014.

8. Baum CE, Stone AP and Tyo JS (eds): Ultra-wideband, short-pulse electromagnetics. 8th edition. New York: Springer, 2007.

9. Wu L, Yao C, Xiong Z, Zhang R, Wang Z, Wu Y, Qin Q and Hua Y: The effects of a picosecond pulsed electric field on angiogenesis in the cervical cancer xenograft models. Gynecol Oncol 141: 175-181, 2016.

10. Arnaoutova I, George J, Kleinman HK and Benton G: The endothelial cell tube formation assay on basement membrane turns 20: State of the science and the art. Angiogenesis 12: 267-274, 2009.

11. Hua YY, Wang XS, Zhang Y, Yao CG, Zhang XM and Xiong ZA: Intense picosecond pulsed electric fields induce apoptosis through a mitochondrial-mediated pathway in HeLa cells. Mol Med Rep 5: 981-987, 2012.

12. Folkman J: The role of angiogenesis in tumor growth. Semin Cancer Biol 3: 65-71, 1992.

13. Eskander RN and Tewari KS: Targeting angiogenesis in advanced cervical cancer. Ther Adv Med Oncol 6: 280-292, 2014.

14. Kerbel RS: Tumor angiogenesis. N Engl J Med 358: 2039-2049, 2008.

15. Erös de Bethlenfalva-Hora C, Mertens JC, Piguet AC, Kettenbach J, Schmitt J, Terracciano L, Weimann R, Dufour JF and Geier A: Radiofrequency ablation suppresses distant tumour growth in a novel rat model of multifocal hepatocellular carcinoma. Clin Sci (Lond) 126: 243-252, 2014.

16. Groblewska M, Siewko M, Mroczko B and Szmitkowski M: The role of matrix metalloproteinases (MMPs) and their inhibitors (TIMPs) in the development of esophageal cancer. Folia Histochem Cytobiol 50: 12-19, 2012.

17. Carmeliet $P$ and Jain RK: Molecular mechanisms and clinical applications of angiogenesis. Nature 473: 298-307, 2011.

18. Ribatti D: Genetic and epigenetic mechanisms in the early development of the vascular system. J Anat 208: 139-152, 2006.

19. Denekamp J, Hill SA and Hobson B: Vascular occlusion and tumour cell death. Eur J Cancer Clin Oncol 19: 271-275, 1983.

20. Hajitou A, Grignet C, Devy L, Berndt S, Blacher S, Deroanne CF, Bajou K, Fong T, Chiang Y, Foidart JM and Noël A: The antitumoral effect of endostatin and angiostatin is associated with a down-regulation of vascular endothelial growth factor expression in tumor cells. FASEB J 16: 1802-1804, 2002.

21. Kaur B, Khwaja FW, Severson EA, Matheny SL, Brat DJ and Van Meir EG: Hypoxia and the hypoxia-inducible-factor pathway in glioma growth and angiogenesis. Neuro Oncol 7: 134-153, 2005.

22. Chaplin DJ and Horsman MR: The influence of tumour temperature on ischemia-induced cell death: Potential implications for the evaluation of vascular mediated therapies. Radiother Oncol 30: 59-65, 1994.

23. Noguera R, Fredlund E, Piqueras M, Pietras A, Beckman S, Navarro S and Påhlman S: HIF-1alpha and HIF-2alpha are differentially regulated in vivo in neuroblastoma: High HIF-1alpha correlates negatively to advanced clinical stage and tumor vascularization. Clin Cancer Res 15: 7130-7136, 2009.

24. Brown JM and Wilson WR: Exploiting tumour hypoxia in cancer treatment. Nat Rev Cancer 4: 437-447, 2004.

25. Vaupel P and Mayer A: Hypoxia in tumors: Pathogenesis-related classification, characterization of hypoxia subtypes, and associated biological and clinical implications. Adv Exp Med Biol 812: 19-24, 2014.

This work is licensed under a Creative Commons Attribution-NonCommercial-NoDerivatives 4.0 International (CC BY-NC-ND 4.0) License. 